\title{
Essentiality of Circulating Fatty Acids for Glucose-stimulated Insulin Secretion in the Fasted Rat
}

\author{
Daniel T. Stein, ${ }^{*}$ Victoria Esser, ${ }^{*}$ Brent E. Stevenson, ${ }^{\star}$ Kirk E. Lane, ${ }^{*}$ James H. Whiteside, ${ }^{\star}$ Murphy B. Daniels, ${ }^{\star}$ \\ Songyuan Chen, ${ }^{\star}$ and J. Denis McGarry ${ }^{\star \ddagger}$ \\ Departments of $*$ Internal Medicine and ${ }^{\ddagger}$ Biochemistry, Gifford Laboratories, Center for Diabetes Research, University of Texas \\ Southwestern Medical Center at Dallas, Dallas, Texas 75235
}

\begin{abstract}
We asked whether the well known starvation-induced impairment of glucose-stimulated insulin secretion (GSIS) seen in isolated rat pancreas preparations also applies in vivo. Accordingly, fed and 18-24-h-fasted rats were subjected to an intravenous glucose challenge followed by a hyperglycemic clamp protocol, during which the plasma-insulin concentration was measured. Surprisingly, the acute (5 $\mathrm{min}$ ) insulin response was equally robust in the two groups. However, after infusion of the antilipolytic agent, nicotinic acid, to ensure low levels of plasma FFA before the glucose load, GSIS was essentially ablated in fasted rats, but unaffected in fed animals. Maintenance of a high plasma FFA concentration by coadministration of Intralipid plus heparin to nicotinic acid-treated rats (fed or fasted), or further elevation of the endogenous FFA level in nonnicotinic acidtreated fasted animals by infusion of etomoxir (to block hepatic fatty acid oxidation), resulted in supranormal GSIS. The in vivo findings were reproduced in studies with the perfused pancreas from fed and fasted rats in which GSIS was examined in the absence and presence of palmitate. The results establish that in the rat, the high circulating concentration of FFA that accompanies food deprivation is a sine qua non for efficient GSIS when a fast is terminated. They also serve to underscore the powerful interaction between glucose and fatty acids in normal $\beta$ cell function and raise the possibility that imbalances between the two fuels in vivo could have pathological consequences. (J. Clin. Invest. 1996. 97:2728-2735.) Key words: insulin secretion • stimulus-secretion coupling • fatty acids • nicotinic acid • antilipolysis
\end{abstract}

\section{Introduction}

The effects of starvation on the metabolic profiles of tissues such as liver, muscle, and fat have been intensively investigated and are widely discussed in the literature. Less well ap-

Songyuan Chen's present address is Department of Diabetes, Endocrinology, and Metabolism, City of Hope Medical Center, Duarte, CA 91010.

Address correspondence to J. Denis McGarry, Professor of Internal Medicine and Biochemistry, U.T. Southwestern Medical Center at Dallas, 5323 Harry Hines Blvd., Dallas, TX 75235. Phone: 214-6483484; FAX: 214-648-2843.

Received for publication 22 December 1995 and accepted in revised form 18 March 1996.

J. Clin. Invest.

(C) The American Society for Clinical Investigation, Inc. 0021-9738/96/06/2728/08 \$2.00

Volume 97, Number 12, June 1996, 2728-2735 preciated, however, is the remarkable influence that fasting has on the functioning of the pancreatic $\beta$ cell. This point, which has been recognized for some three decades (1), and has been reexamined sporadically in the intervening years (2-13), is well illustrated by the studies of Burch et al. (8). These authors fasted normal rats for increasing periods of time, and then measured the ability of their isolated pancreatic islets to secrete insulin when perifused with a solution containing 10 $\mathrm{mM}$ glucose. The striking observation was that after only $24 \mathrm{~h}$ of food deprivation, glucose-stimulated insulin secretion

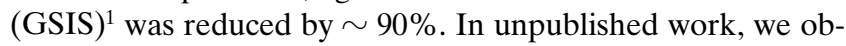
tained similar results using the intact perfused rat pancreas preparation. Although a number of attempts have been made to explain the phenomenon (1-13), a satisfactory answer has yet to emerge.

The current studies were prompted by the following consideration: if, during the feeding/fasting cycle, the $\beta$ cell were to behave in vivo as it does in vitro, then one might expect that when challenged with a glucose load, a rat previously fasted for $\sim 24$ h would display a profoundly diabetic profile (i.e., it should exhibit little or no insulin secretion, coupled with a severe and protracted phase of hyperglycemia). But this is not the case. As will be seen below, such animals respond to glucose with an acute insulin response of similar magnitude to that observed in fed rats. The solution to the paradox turned out to be intriguing and, we believe, potentially far reaching for an understanding of $\beta$ cell physiology - in rats deprived of food for 18-24 h, the ability of the $\beta$ cell to secrete insulin in response to a glucose load is absolutely dependent upon the elevated level of circulating FFA characteristic of the fasted state.

\section{Methods}

Animals. Male Sprague-Dawley rats (Harlan Sprague-Dawley Co., Indianapolis, IN) weighing $\sim 300 \mathrm{~g}$ were anesthetized with ketamine/ xylazine and fitted with carotid (PE 50; Clay Adams, Parsippany, NJ) and jugular (Micro-renathane, $0.025 \times 0.04 ")$ catheters (Braintree Scientific, Inc., Braintree, MA). Some animals also received a gastric catheter (PE 90; Clay Adams). The catheters were exteriorized in the posterior neck, filled with Povidone-10/glycerol/heparin (160\% (wt/ vol) polyvinylpyrrolidone, $20 \%$ (wt/vol) glycerol, and $150 \mathrm{U} / \mathrm{ml}$ heparin in saline), and closed at the ends with metal plugs. The animals were maintained for at least $5 \mathrm{~d}$ on a light/dark cycle (lights on 1000 to 2200 hours) with ad libitum access to standard rodent chow (4\% fat) (Harlan Teklad, Madison, WI). Fasted rats were deprived of food from 1800 hours the night before the experiments.

Hyperglycemic clamp. On the morning of the experiments $(\sim 0900$ $\mathrm{hr}$ ), catheters were flushed with small amounts of heparinized saline ( $25 \mathrm{U} / \mathrm{ml})$, after which the arterial line was connected for infusion of

1. Abbreviations used in this paper: CPT, carnitine palmitoyltransferase; FA-CoA, fatty acyl-CoA; GSIS, glucose-stimulated insulin secretion; NA, nicotinic acid. 
test substances and replacement blood; the venous line was used for sampling and was kept patent by the infusion of heparinized saline at $1 \mathrm{ml} / \mathrm{h}$. After a $60 \mathrm{~min}$ equilibration phase $(-60$ to $0 \mathrm{~min}$, basal period), glucose was given to fasted rats as an intravenous bolus of 375 $\mathrm{mg} / \mathrm{kg}$ over a 1-min interval and was subsequently infused as a $25 \%$ $(\mathrm{wt} / \mathrm{vol})$ solution in amounts required to maintain the plasma concentration constant at $\sim 200 \mathrm{mg} / \mathrm{dl}$. Fed animals were treated similarly except that the glucose bolus was reduced by $20 \%$ to match their peak plasma glucose levels with those of the fasted group. Blood was taken every 5-10 min for plasma glucose measurements. Additional samples were obtained at $-60,0,5,10,15,30,45$, and $60 \mathrm{~min}$. These were immediately placed into cold heparin/lithium-coated microfuge tubes and centrifuged. The plasma was then frozen in liquid $\mathrm{N}_{2}$ and stored at $-20^{\circ} \mathrm{C}$ until analyzed for other components (generally within 1-4 d). Blood was quantitatively replaced via the arterial line $(2 \mathrm{ml} / \mathrm{h}$ ) as a mixture consisting of washed red cells suspended in $10 \%$ fed-rat serum that had been dialyzed against Krebs bicarbonate buffer, $\mathrm{pH}$ 7.4.

Most test substances were dissolved in $150 \mathrm{mM} \mathrm{NaCl}$ containing $10 \%$ dialyzed rat serum and adjusted to $\mathrm{pH} 6.5-8$ where necessary. Each was given as a $0.25-\mathrm{ml}$ bolus at $-60 \mathrm{~min}$, followed by constant infusion at $1.5 \mathrm{ml} / \mathrm{h}$. Infusate concentrations were: nicotinic acid (Sigma Chemical Co., St. Louis, MO), $20 \mathrm{mM}$; glycerol, $0.4 \mathrm{M}$; etomoxir (14), $0.4 \mathrm{mM}$; sodium D- $\beta$-hydroxybutyrate (Sigma Chemical Co.) plus sodium acetoacetate (prepared as in reference 15) in various ratios to give a total concentration of 0.5 or $1 \mathrm{M}$. Intralipid (Kabi Pharmacia, Clayton, NC) was infused as a $20 \%$ emulsion (without bolus) at $0.4 \mathrm{ml} / \mathrm{h}$ per $100 \mathrm{~g}$ body wt. In this case, the animals also received intravenous boluses of 100,50 , and $25 \mathrm{U}$ of heparin at -60 , -30 , and $0 \mathrm{~min}$, respectively.

Gastric infusion. In one series of experiments, the glucose was given at $0 \mathrm{~min}$ as an intragastric bolus over $2 \mathrm{~min}$ in the amount of 1,000 and $800 \mathrm{mg} / \mathrm{kg}$ to fasted and fed rats, respectively. Other procedures were as described above.

Pancreas perfusion. Pancreases were perfused essentially as described previously (16). The basal perfusate, maintained at $37^{\circ} \mathrm{C}$ under an atmosphere of $95 \% \mathrm{O}_{2}$ and $5 \% \mathrm{CO}_{2}$, contained Krebs-Ringer bicarbonate buffer, $\mathrm{pH} 7.4,3 \mathrm{mM}$ glucose, $4.5 \%$ (wt/vol) Dextran T-70 and $1 \%$ (wt/vol) fatty acid-free bovine serum albumin (Sigma Chemical Corp.). When used, sodium palmitate was present at a concentration of $0.5 \mathrm{mM}$ throughout. An equilibration period of $\sim 15$ min was allowed before the start of the actual experiment, which was designated $0 \mathrm{~min}$. After another $10 \mathrm{~min}$, glucose was infused from a syringe to raise its concentration in the perfusate to $12.5 \mathrm{mM}$. At the 40-min time point, this infusion was stopped and the perfusion was continued for another $10 \mathrm{~min}$. Flow rate was $\sim 1.5 \mathrm{ml} / \mathrm{min}$. The effluent was collected in chilled tubes and, after storage at $-20^{\circ} \mathrm{C}$, was assayed for insulin within 1-3 d.

Analyses on plasma and perfusion fluid. Glucose concentrations were measured using a Glucose Analyzer II (Beckman Instruments, Inc., Fullerton, CA). Acetoacetate and $\beta$-hydroxybutyrate levels were determined spectrophotometrically (15). A calorimetric assay employing fatty acyl-CoA synthetase, acyl-CoA oxidase and a peroxidase-linked dye reagent (Boehringer Mannheim Corp., Indianapolis, IN) was employed for the measurement of free fatty acids.

Insulin levels were determined using a modified commercial double antibody radioimmunoassay procedure. ${ }^{125}$ I-labeled rat-insulin, guinea pig antiinsulin antibody, goat anti-guinea pig antibody, normal guinea pig carrier serum and rat insulin standards (lot \# 1026 and 1027) were obtained from LINCO (St. Charles, MO). Plasma samples or insulin standards $(100 \mu \mathrm{l})$ were incubated together with tracer and antiserum in a total volume of $0.3 \mathrm{ml}$ for $24 \mathrm{~h}$ at $4^{\circ} \mathrm{C}$ in polystyrene tubes. All reagents were solubilized in assay buffer containing $50 \mathrm{mM}$ sodium phosphate, $\mathrm{pH} 7.4,25 \mathrm{mM}$ EDTA, $0.01 \%$ sodium azide, $1 \%$ RIA-grade albumin, and $0.25 \%$ Nonidet P- 40 . After precipitation with the polyethylene glycol-8000 second-antibody system, bound insulin was detected in a gamma counter and standard curves were constructed after log-logit transformation of the binding data. No plasma effect on specific or nonspecific binding was noted. Nonspecific binding was consistently less than $2 \%$ of total counts. The minimum detection limit of the assay was $40 \mathrm{pg} / \mathrm{ml}$, with the IC- 80 and IC- 20 values of 0.1 and $1.8 \mathrm{ng} / \mathrm{ml}$, respectively. The interassay coefficients of variation were 9.7 and $5.9 \%$ at the IC- 80 and IC-20, respectively.

\section{Results}

In the first series of experiments (Fig. 1), fed and fasted rats were subjected to the hyperglycemic clamp protocol described in Methods. During the basal period ( -60 to $0 \mathrm{~min}$ ), the plasma glucose concentration was higher in the fed animals, as expected, but after delivery of the intravenous glucose bolus and institution of the clamp, essentially identical plasma glucose profiles were achieved in the two groups (Fig. $1 A$ ). Although the fed rats exhibited higher plasma insulin levels both before and during the clamp, the point to be emphasized is that the acute $(0-5 \mathrm{~min})$ incremental rise in insulin concentration in response to the glucose load was similar in both groups of animals (Fig. $1 \mathrm{C}$ ). Plasma FFA and ketone concentrations fell sharply in response to the glucose-stimulated surge of insulin secretion, the changes being more obvious in fasted animals because of their much higher initial levels of both substrates (Fig. 1, $D$ and $E$ ).

As noted in the Introduction (see also below), when rats are deprived of food for a period of $24 \mathrm{~h}$, the acute insulin response to an elevated glucose concentration in isolated pan-

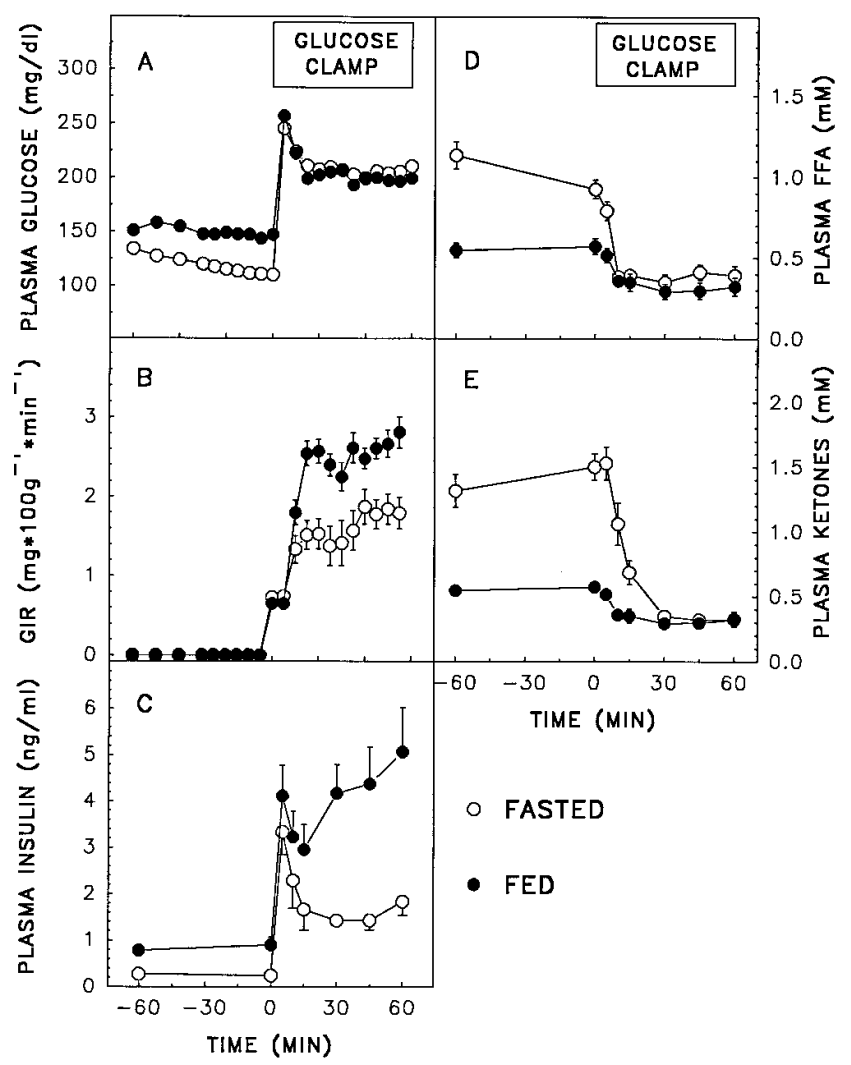

Figure 1. Responses to a hyperglycemic clamp in fed and fasted rats. After the basal period ( -60 to $0 \mathrm{~min}$ ), animals received an i.v. glucose bolus followed by a constant infusion of glucose to maintain a plasma concentration of $\sim 200 \mathrm{mg} / \mathrm{dl}$. GIR, glucose infusion rate. Values are means \pm SEM for 8-14 animals, depending upon the parameter measured. 
creas preparations is greatly attenuated. The fact that this is clearly not true in vivo (Fig. $1 C$ ) suggested that $(a)$ some factor(s), which is present in vivo but absent in vitro, works synergistically with glucose to elicit insulin secretion in the intact fasted animal, and $(b)$ this factor(s) is not essential for GSIS in the fed state either in an in vivo or in vitro setting. Two plausible candidates immediately suggest themselves, namely, FFA and ketone bodies, both of which are known to be capable of stimulating insulin secretion under certain circumstances (see Discussion). Accordingly, we made use of the antilipolytic agent, nicotinic acid (NA)(17), to suppress the high levels of FFA and ketones in fasted rats before initiating the hyperglycemic clamp. The effectiveness of NA on both parameters is illustrated in Fig. 2, $D$ and $E$. Regardless of their initial (-60 min) values, plasma FFA and ketone concentrations fell precipitously during the first hour of infusion in all animals receiving NA and remained very low for the remainder of the experiment. In fact, with NA treatment, fasted rats tended to become hypoglycemic during the basal period. This was no doubt due to diminished hepatic glucose output (stemming from the NA-induced restriction of hepatic fatty acid oxidation, and thus of gluconeogenesis, references 18, 19), coupled with enhanced peripheral glucose uptake (because of the reduced concentrations of competing lipid substrates for oxidation in muscle tissue, references 18, 19). In any event, basal euglycemia was maintained in these animals by infusing small amounts of glucose (Fig. 2, $A$ and $B$ ). The key finding was that,

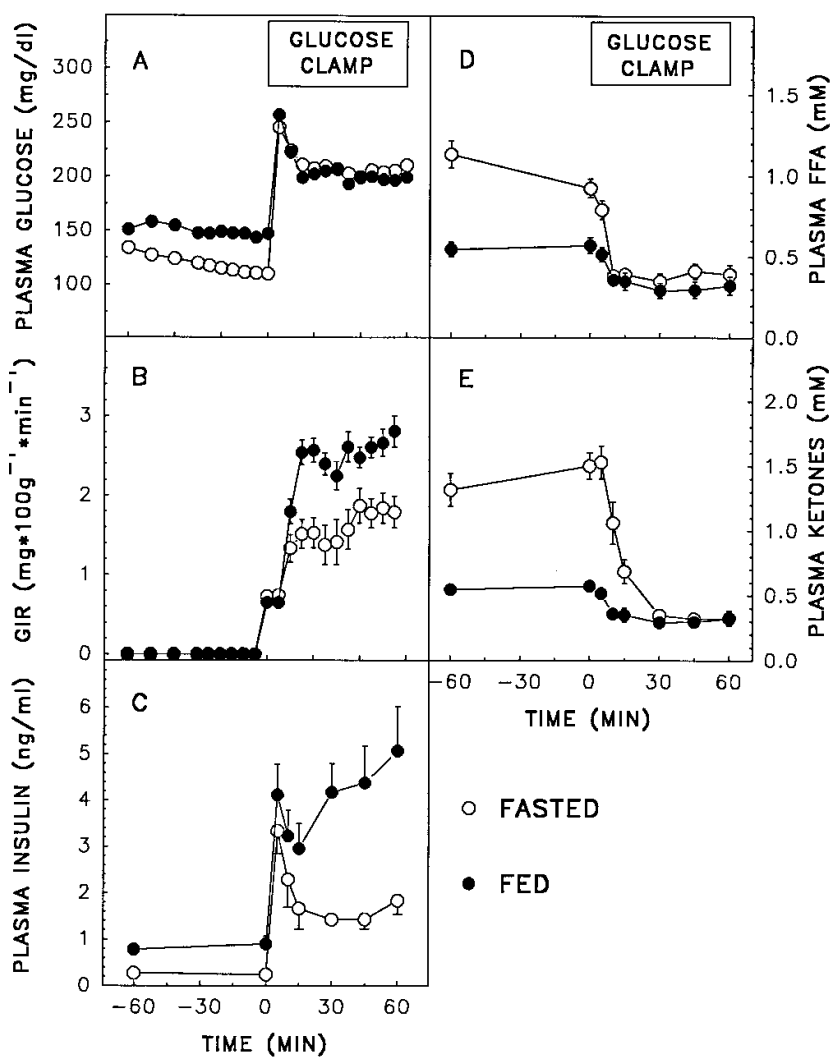

Figure 2. Effect of NA on responses of fed and fasted rats to a hyperglycemic clamp. The basic protocol was as described for Fig. 1, except that NA was infused from -60 min onwards. GIR, glucose infusion rate. Values are mean \pm SEM for 6-11 animals, depending upon the parameter measured. Control data (broken lines) are taken from Fig. 1. upon subsequent acute elevation of the plasma glucose level, the insulin response in NA-treated fasted rats was virtually abolished (Fig. $2 C$ ). By contrast, GSIS in fed animals was not affected by the antilipolytic agent (Fig. 2 C).

Because NA is not itself inhibitory to pancreatic $\beta$ cell function, as evidenced by the above experiments with fed rats and earlier studies with isolated islets (20), it seemed likely that its ability to inhibit GSIS in fasted animals was secondary to its antilipolytic action. Direct evidence to this effect was obtained in the experiment depicted in Fig. 3. The objective here was to treat fasted rats with NA, but to maintain a high plasma FFA level by coinfusion of a triglyceride emulsion (Intralipid) plus heparin, a well established maneuver that promotes intravascular lipolysis (21). In the three groups of animals depicted, the starting ( $-60 \mathrm{~min}$ ) plasma FFA concentration ranged from $\sim 1.2-1.5 \mathrm{mM}$ (Fig. $3 \mathrm{D}$ ). Instead of falling to almost undetectable levels at $0 \mathrm{~min}$, as in rats given NA only, the value rose to $\sim 2.5 \mathrm{mM}$ in those receiving NA plus exogenous lipid and heparin, and remained elevated throughout the experiment. Plasma ketones displayed a similar profile (Fig. $3 E$ ). Although the manipulation had little impact on the very low basal insulin level, the effect on insulin secretion during the glucose clamp was profound. Not only did the 0-5 min response rise from zero (as in the NA-only group) to $\sim 60 \%$ of that in vehicletreated rats, but the rate of hormone secretion increased continuously thereafter (assuming that clearance did not change),

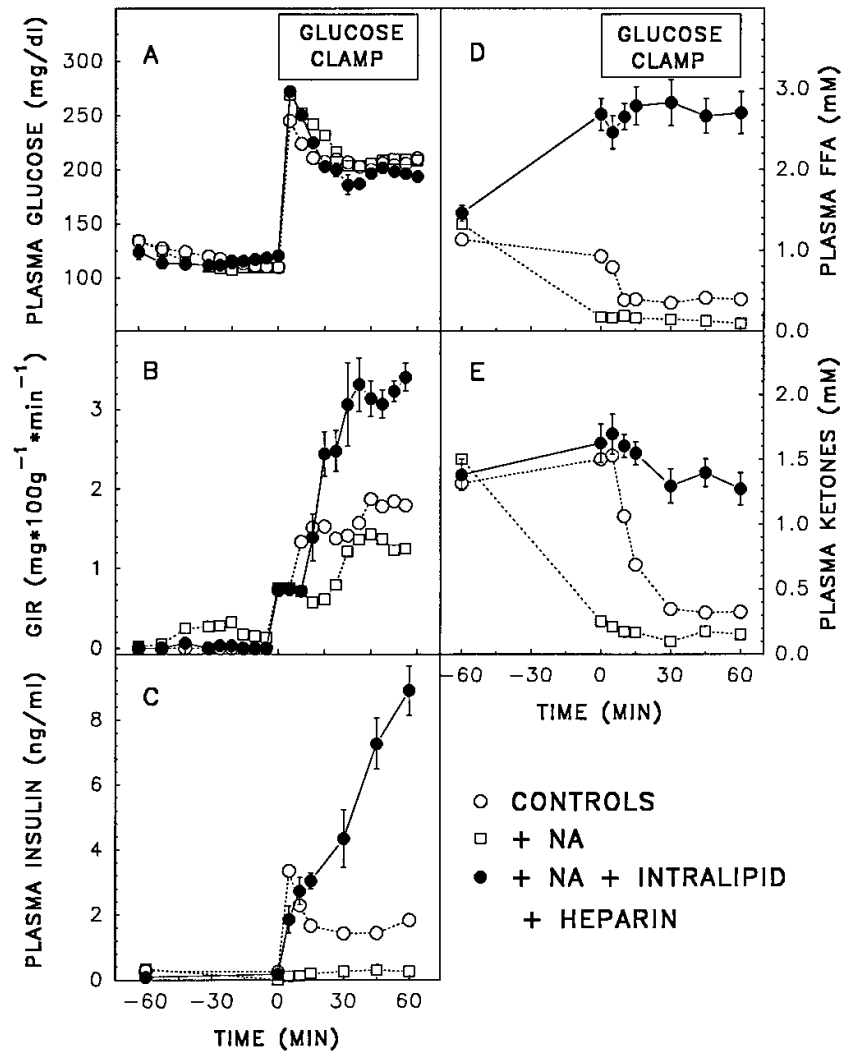

Figure 3. Effect of coinfusion of lipid and NA on responses of fasted rats to a hyperglycemic clamp. The basic protocol was as described for Figs. 1 and 2, except that NA and Intralipid were infused from -60 min onward and heparin was administered at $-60,-30$, and 0 min. GIR, glucose infusion rate. Values are mean \pm SEM for 5 animals. Data for animals receiving vehicle or NA only (broken lines) are taken from Figs. 1 and 2, respectively. 
such that the total area under the curve far exceeded that in the control group (Fig. $3 C$ ).

When the same type of experiment was conducted with fed animals, the powerful stimulus to insulin secretion by artificial elevation of the plasma FFA concentration was even more striking. In this case, there was a clear increase in basal insulin levels and an even more dramatic enhancement in hormone secretion following glucose administration (Fig. 4).

In light of this pronounced effect of exogenous fatty acids, we asked whether elevation of the already high endogenous plasma FFA level would further enhance GSIS in fasted rats. To this end, animals were treated with etomoxir, a well known inhibitor of mitochondrial carnitine palmitoyltransferase (CPT) I, the enzyme catalyzing the first step in long chain fatty-acid oxidation (22). For these studies, we purposely chose an infusion rate of etomoxir that caused a rapid and complete block of liver CPT I while leaving the enzyme in skeletal muscle and islet cells largely unaffected. ${ }^{2}$ By suppressing hepatic fatty acid oxidation, which accounts for a significant proportion of FFA turnover in the fasted state, etomoxir infusion from -60 min resulted in a plasma FFA level at 0 min of $\sim 2$ $\mathrm{mM}$, compared with $\sim 1 \mathrm{mM}$ in the vehicle-treated rats (Fig. 5 $D$ ), and a major reduction in the degree of ketonemia (Fig. 5 $E)$. Upon subsequent challenge with glucose, the acute insulin response in animals receiving etomoxir was $\sim 50 \%$ higher $(P<$ 0.05 ) than in the control group (Fig. $5 C$ ). The potent antilipolytic effect of the high initial insulin output in control and etomoxir-treated animals is reflected in the rapid fall of their plasma FFA concentration (Fig. $5 \mathrm{D}$ ). This contrasts with the situation in animals receiving an exogenous source of FFA (Fig. $3 \mathrm{D}$ ) and probably accounts for why insulin levels declined over the 5 to $60 \mathrm{~min}$ interval in the former groups (Fig. 5C); whereas they continuously increased in the latter (Fig. $3 C$ ). That the stimulatory effect of etomoxir on GSIS in the experiment of Fig. 5 was FFA-mediated was established by infusing a third group of rats with the CPT I inhibitor plus NA. In this case, FFA essentially disappeared from the plasma (Fig. $5 \mathrm{D}$ ) and there was little insulin secretion following the glucose challenge (Fig. 5 C).

2. The ability of etomoxir to inhibit fatty acid oxidation in a given cell type depends upon three factors: $(a)$ the efficiency of cellular uptake of the compound; $(b)$ the cell's capacity to activate the material to its CoA ester; and $(c)$ the ability of the ester to interact covalently with CPT I on the outer mitochondrial membrane. Note that CPT II (inner mitochondrial membrane) is insensitive to etomoxir-CoA (23). To examine the effectiveness of etomoxir as used here, four fasted rats were infused with the agent from $-60 \mathrm{~min}$ as in the studies described in Fig. 5. At the +15 -min time point, the animals were anesthetized with Nembutal, after which their pancreatic islets were isolated (16), pooled and homogenized in $0.15 \mathrm{M} \mathrm{KCl} / 5 \mathrm{mM}$ Tris- $\mathrm{HCl}$, $\mathrm{pH}$ 7.2. The liver and combined gastrocnemius/soleus muscles were also removed from three rats and used independently for the preparation of mitochondria (23). Activities of CPT I and CPT II were then measured in each batch of mitochondria and in the islet homogenate as described previously (23). The CPT II/CPT I activity ratios for each rat were: liver mitochondria, 125,112 , and $\infty$; muscle mitochondria, 2.1, 2.4, and 2.8; islet homogenate (pool), 3.7. In parallel studies on animals not receiving etomoxir the equivalent values were: liver mitochondria 2.2, 2.7, and 2.6; muscle mitochondria, 1.6, 1.6, and 1.9; islet homogenate, 6.5. Clearly, the dosage of etomoxir used here caused essentially total inhibition of CPT I in liver while having only a small or no effect on the enzyme in muscle or islets.

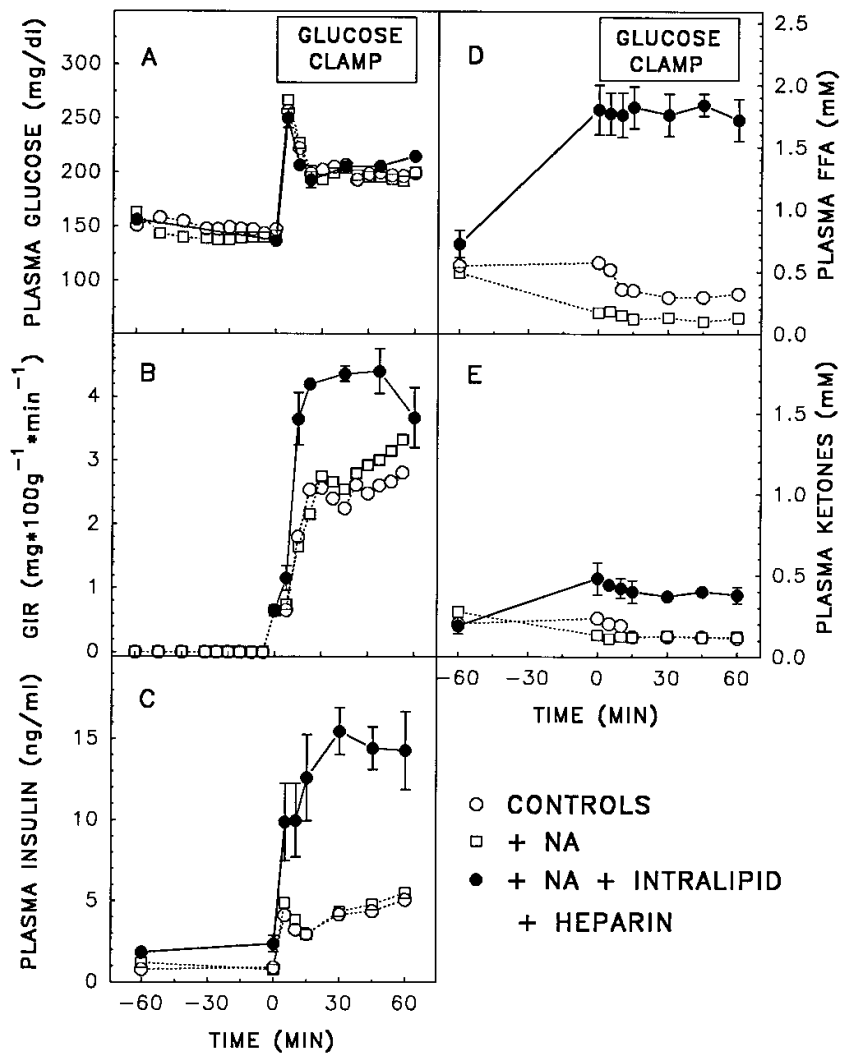

Figure 4. Effect of coinfusion of lipid and NA on responses of fed rats to a hyperglycemic clamp. The protocol was as described in Fig. 3. GIR, glucose infusion rate. Values are mean \pm SEM for 4 animals. Data for animals receiving vehicle or NA only (broken lines) are taken from Figs. 1 and 2, respectively.

It was possible that the stimulatory effect on GSIS ascribed to fatty acids in the above experiments was not direct, but was mediated by the ketone bodies, which are products of fatty acid metabolism, and generally fluctuated in concentration in parallel with FFA. Although this seemed unlikely given the opposite directional changes in FFA and ketone levels in etomoxir-treated rats (Fig. 5), we tested the possibility more directly as follows: two groups of fasted rats received NA as in the previous experiments, but, in addition, were given a mixture of sodium acetoacetate and sodium $\mathrm{D}-\beta$-hydroxybutyrate in different amounts and ratios from the -60 -min time point (see Methods). The standard protocol was then followed. The total circulating ketone concentrations achieved at $0 \mathrm{~min}$ in the "low" and "high ketone" infused groups were $\sim 0.9$ and 2.3 $\mathrm{mM}$, respectively, and these were more or less maintained throughout the subsequent hyperglycemic clamp (Fig. 6E). By comparison, the 0 -min ketone levels in rats receiving vehicle or NA only was $\sim 1.5$ and $0.2 \mathrm{mM}$, respectively. Despite the substantial circulating concentration of ketone bodies in the low ketone-infused animals, this had essentially no impact on the severe NA-induced suppression of GSIS (Fig. $6 C$ ). Even with the high rate of ketone replacement, the first-phase insulin response to hyperglycemia was still only $\sim 30 \%$ of that seen in the vehicle controls, although at later time points insulin concentrations in these two groups became closer. While it is conceivable that this modest stimulatory effect on insulin secretion was due, at least in part, to the supranormal level of ketone 


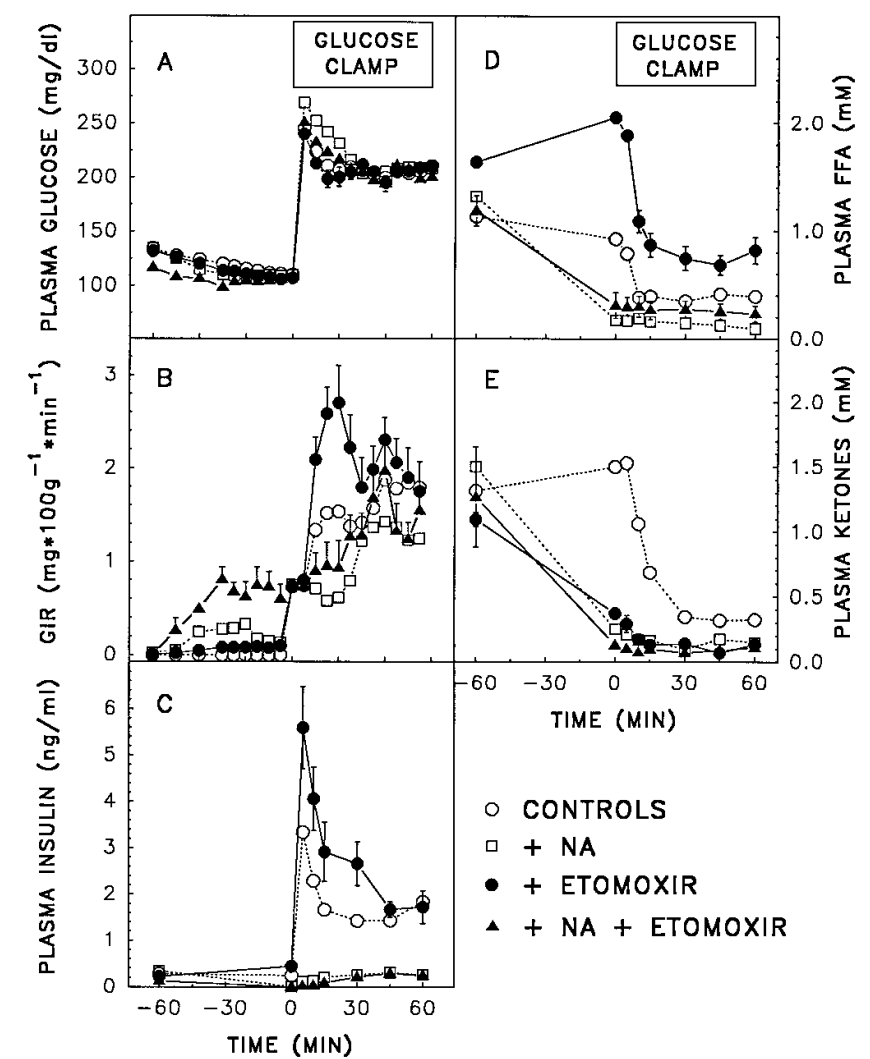

Figure 5. Effect of etomoxir on responses of fasted rats to a hyperglycemic clamp. The basic protocol was as described for Figs. 1-3, except that etomoxir was infused with or without NA from $-60 \mathrm{~min}$ onwards. GIR, glucose infusion rate. Values are mean \pm SEM for 5-7 animals, depending upon the parameter measured. Data for animals receiving vehicle or NA only (broken lines) are taken from Figs. 1 and 2 , respectively.

bodies, we suspect that once again the more important factor was FFA. Note that with the high ketone infusion rate, the NA-induced fall of plasma FFA was not as pronounced as in the other groups (Fig. $6 \mathrm{D}$ ), possibly because of competition between ketone bodies and FFA for clearance in nonhepatic tissues.

In experiments not shown, NA-treated fasted rats received an exogenous infusion of glycerol to raise the plasma concentration to $\sim 1 \mathrm{mM}$, which was much higher than in the control group. This produced no relief of their blunted GSIS.

Panel $B$ of Figs. 1-6 shows the glucose infusion rate $(G I R)$ required to maintain a plasma glucose concentration of $\sim 200$ $\mathrm{mg} / \mathrm{dl}$ during the various manipulations. In general, this appeared to be dictated primarily by changes in insulin secretion, although undoubtedly the different rates reflected a complex interplay between insulin, glucose, and FFA on hepatic glucose output and peripheral substrate use. We did not examine the issue further.

All of the above studies addressed the role of plasma FFA on GSIS when fasted rats were given the glucose load intravenously. The question arose as to whether the findings had relevance to the more physiological situation where glucose is delivered into the stomach. To this end, studies similar to those described in Figs. 1-6 were conducted with fasted rats that had been fitted with a gastric catheter through which a glucose bolus was delivered at the 0-min time point. As illustrated in Fig. $7 A$, the plasma glucose profiles in control and NA-treated an-

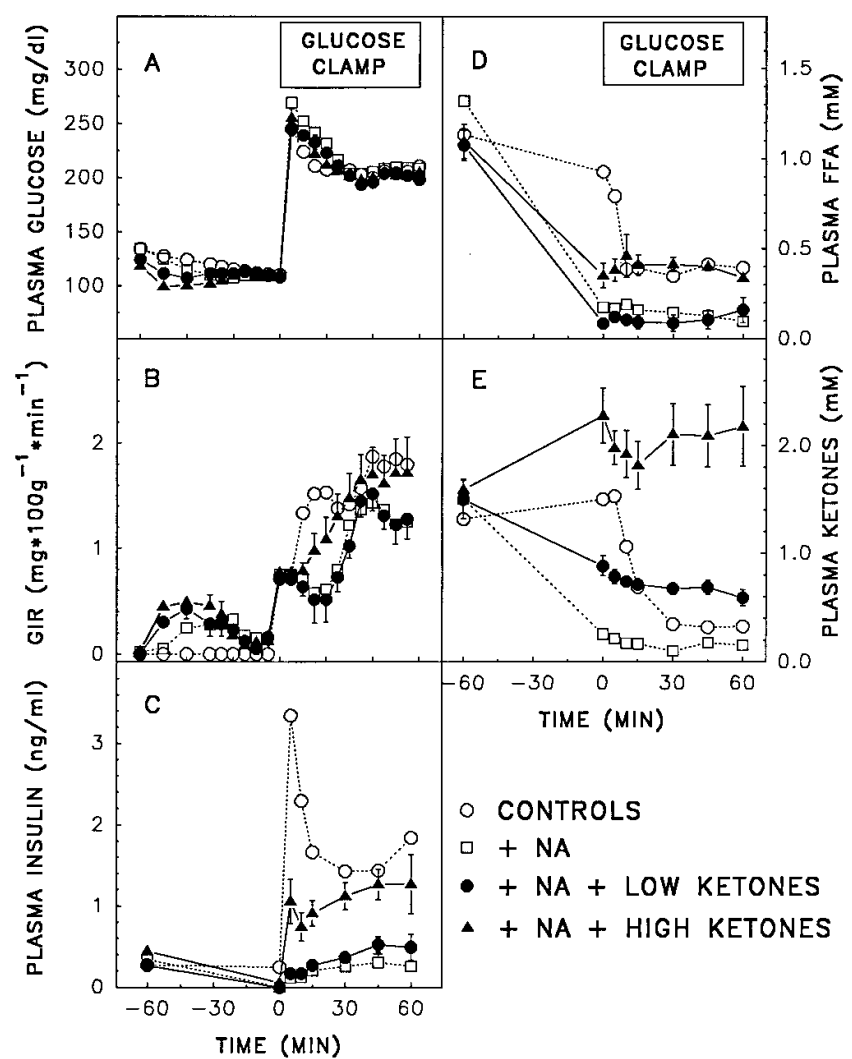

Figure 6. Effect of coinfusion of ketone bodies and NA on responses of fasted rats to a hyperglycemic clamp. The basic protocol was as described for Fig. 3, except that a mixture of acetoacetate and $\beta$-hydroxybutyrate was infused at a low or a high rate (see Methods) from -60 min onwards. In both cases, the plasma $\beta$-hydroxybutyrate/acetoacetate ratio at 0 min was $\sim 0.4$; the value in controls was $\sim 0.6$. GIR, glucose infusion rate. Values are mean \pm SEM for 5-6 animals, depending upon the parameter measured. Data for animals receiving vehicle or NA only (broken lines) are taken from Figs. 1 and 2, respectively.

imals were similar throughout the experiment. However, during the first $10 \mathrm{~min}$ after the glucose load, the sharp increase in plasma insulin levels seen in the controls was totally suppressed in the NA-infused rats (Fig. 7 B). Although the latter group did show evidence of insulin secretion during the subsequent $20 \mathrm{~min}$ (possibly due to an incretin effect), the total area under the curve was much smaller than in the controls. The data clearly indicate that in the 18-24-h fasted rat, circulating FFA are critically important for GSIS regardless of the route of administration of the glucose load.

Finally, these findings in the intact rat provided a clue as to why, in earlier experiments with isolated pancreas preparations, GSIS was invariably found to be severely depressed after simple starvation of the donor animals (1, 3-13). Might this have been due, at least in part, to the fact that the cited studies were always conducted in the absence of FFA? We have just begun to explore this issue using the perfused pancreas from fed and fasted rats. Though admittedly limited in scope, the initial results (Fig. 8) reveal several important points. First, in control perfusions, insulin secretion during the basal period (3 $\mathrm{mM}$ glucose) was very low to undetectable, regardless of nutritional state. Second, raising the glucose concentration to 12.5 $\mathrm{mM}$ in the absence of fatty acid-enhanced insulin release from 


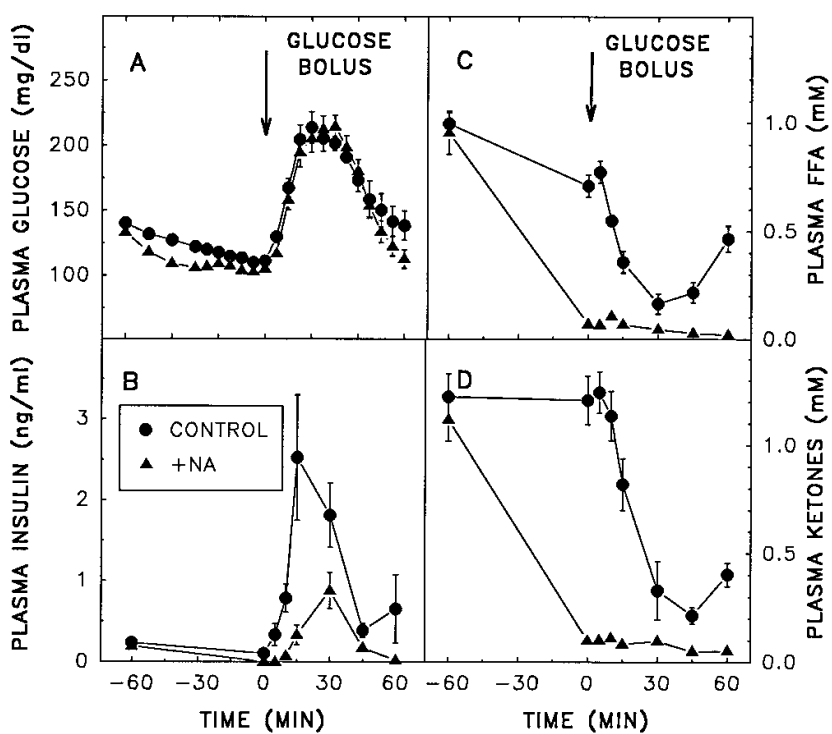

Figure 7. Effect of nicotinic acid on responses of fasted rats to intragastric glucose. Animals were infused with vehicle or NA from -60 min onwards as described in Fig. 2 and, at 0 min, a glucose bolus was given intragastrically (see Methods). Values are mean \pm SEM for 5-10 rats depending upon the parameter measured.

the "fed" pancreas, as expected, but the response was reduced by $\sim 80 \%$ after the 18-24-h fast (in keeping with earlier reports, references $1,3-8,13$ ). Third, and particularly impressive, the simple addition of $0.5 \mathrm{mM}$ palmitate to the perfusion medium boosted GSIS from the "fasted" pancreas some eightfold, such that total hormone output during the 10-40-min interval was now $80 \%$ greater than that from the fed organ challenged with $12.5 \mathrm{mM}$ glucose alone. Finally, the presence of palmitate caused major stimulation of both basal and GSIS from the pancreas of fed animals.

\section{Discussion}

We undertook this investigation in an attempt to reconcile two seemingly conflicting features of pancreatic $\beta$ cell function. In keeping with previous reports $(1,3-13)$, we found in preliminary studies that the ability of a stimulatory concentration of glucose to elicit insulin secretion from the perfused pancreas of fed rats was largely attenuated if the donor animals were first fasted, in our case for a period of 18-24 h. Yet when intact rats were challenged with intravenous glucose, the acute $(5 \mathrm{~min})$ rise in plasma insulin level was equally robust in the two nutri-

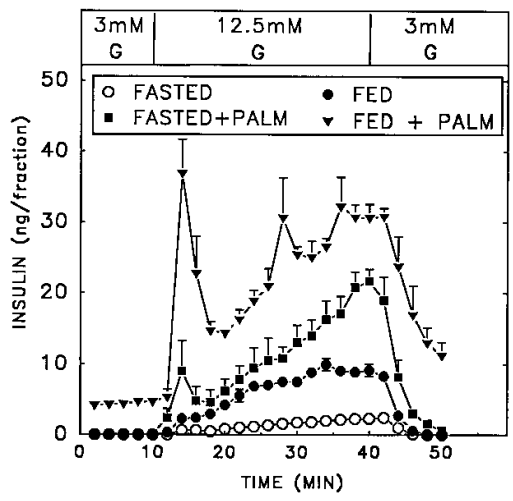

Figure 8. Glucose-stimulated insulin secretion from the perfused pancreas of fed and fasted rats. Pancreases were perfused with the indicated concentration of glucose $(G)$ in the absence or presence of 0.5 $\mathrm{mM}$ palmitate as described in Methods.

Values are

mean \pm SEM for 3-5 animals in each group. tional groups. Both points were confirmed in the present work. From this simple set of observations, two conclusions seemed warranted. First, in the fasted state, GSIS required some additional factor(s) that was present in vivo but not in the in vitro experiments. Second, in the fed state, this component was not needed for efficient GSIS. In considering what such a "glucose cofactor" might be, our attention turned to free fatty acids for the following reasons: $(a)$ an elevated plasma FFA level is one of the hallmarks of the fasted state; $(b)$ it has long been known that FFA are capable of enhancing GSIS both in vivo $(17,24$ 27 ) and in vitro $(9,12,16,28-34)$; and (c) there is growing evidence for an interaction between glucose and fatty acid metabolism as an integral component of stimulus-secretion coupling within the $\beta$ cell (9-12, 16, 33-36; see below).

The experimental approach chosen was to lower the circulating FFA level in fasted rats by infusion of the antilipolytic agent NA, and then examine the plasma insulin profile in response to a hyperglycemic clamp protocol. Remarkably, in animals so treated, GSIS was essentially abolished. In other words, the fasted pancreas now acted in vivo as it did in vitro. These experiments pointed to a critically important role of FFA with regard to GSIS in the fasted state; however, they did not exclude a contribution from ketone bodies (which can stimulate insulin secretion under certain conditions, references 30, 37-39) or glycerol, whose concentrations also fell during NA infusion. Accordingly, other groups of fasted rats received, in addition to NA, a coinfusion of Intralipid plus heparin, acetoacetate plus $\beta$-hydroxybutyrate, or glycerol to maintain high levels of FFA (as well as ketones and glycerol), ketones, or glycerol, respectively. An additional strategy was to treat fasted animals with the CPT I-inhibitor etomoxir under conditions that caused complete inhibition of the enzyme in liver while leaving that in skeletal muscle and the pancreatic $\beta$ cell essentially unaffected. This last maneuver provided a means of sustaining a high level of endogenous plasma FFA while allowing the concentration of ketone bodies to fall dramatically. All animals were then subjected to the hyperglycemic clamp, during which plasma insulin levels were measured. Collectively, the data established two key points. First, in the fasted rat, the principal factor acting in concert with glucose to stimulate insulin secretion was FFA. Second, when FFA levels were elevated artificially, GSIS became supranormal (although basal insulin values were little affected). It was also shown that the dependence of GSIS on circulating FFA in fasted rats was not a peculiarity of $\beta$ cell function in response to intravenously administered glucose. The phenomenon also applied to animals challenged with glucose via the intragastric route. Here again, lowering of FFA levels with NA caused marked attenuation of the early phase of insulin release, although hormone secretion at later time points was more efficient than in the equivalent studies using intravenous glucose, possibly due to an incretin effect of the gastric glucose load.

In contrast to the situation in fasted rats, GSIS in fed animals was totally unaffected by NA (i.e., it was independent of the normal circulating level of FFA, which, in any case, was much lower than in fasted rats). However, here again, administration of Intralipid plus heparin had dramatic effects, causing a significant rise in basal insulin levels and marked potentiation of GSIS.

The conclusions drawn from these experiments in intact animals were reaffirmed in studies with the isolated perfused pancreas. Thus, starvation caused major ( 80\%) suppression 
of insulin secretion following a shift in perfusate glucose concentration from 3 to $12.5 \mathrm{mM}$. However, the problem was readily correctable by the simple inclusion of $0.5 \mathrm{mM}$ palmitate in the medium (as the medium contained 1\% albumin, this would be roughly equivalent to a total FFA level in plasma of $\sim 2 \mathrm{mM}$ ). In fact, under these conditions insulin output from the fasted pancreas exceeded that from its fed counterpart perfused with $12.5 \mathrm{mM}$ glucose alone, although the performance of the latter was also greatly enhanced when the fatty acid was present, in keeping with earlier work $(9,16,34)$.

As noted above, the ability of fatty acids to improve the stimulatory action of glucose on pancreatic insulin release has been reported in different contexts on many previous occasions. What emerges from the current study is a characteristic of $\beta$ cell function that has not been emphasized to date, (i.e., were it not for the elevated circulating level of FFA in the 18$24 \mathrm{~h}$ fasted rat, the pancreas would be largely "blind" to glucose in terms of its ability to secrete insulin during the initial phase of refeeding). An interesting physiological corollary of this conclusion is that, at least in the model studied here, the very same substrates (FFA), whose mobilization from fat depots is a crucially important adaptation to the falling insulin level during the onset of starvation, are essential for the triggering of insulin secretion when the fast is terminated. Stated in another way, FFA are paradoxically instrumental in bringing about their own disappearance from the blood during the fasted to fed transition (by virtue of their synergism with glucose to elicit insulin secretion that, in turn, suppresses adipose tissue lipolysis). Whether FFA play a similar role in the reversal of the fasted state in humans remains to be established. In this regard, it is noteworthy that the term "starvation diabetes" was used to describe the dampened insulin response to oral or intravenous glucose in humans previously fasted for 3-8 d (40, 41). But careful inspection of those reports reveals that the acute rise in plasma insulin concentration was not profoundly diminished in the study subjects, particularly when considered in conjunction with the degree of hyperglycemia achieved. Noteworthy, however, are the very high plasma FFA levels measured just before administration of the glucose load, as expected after such prolonged fasting periods. We consider it likely that these played a key role in permitting insulin secretion following the influx of glucose.

At the biochemical level, a challenging question is now posed: why does the fasted islet become desensitized to glucose when this is present as the sole insulin secretagogue? One theory ascribed the problem to a starvation-induced loss of glucose-mediated cyclic AMP generation within the $\beta$ cell (4, 7). Another suggested that starvation brings about inhibition of an early step(s) in glycolysis, in particular glucokinase $(5,6$, $8,11,13)$, or of glucose transport (13). While such derangements might play some role, what must now be factored into the discussion is that the defect in GSIS caused by food deprivation is completely alleviated if FFA are also present. It might be argued that with fasting there is a $\beta$ cell impairment of energy generation from glucose and that the role of FFA is simply to offset the defect. However, if FFA were simply providing the $\beta$ cell with energy, one might expect that mediumchain fatty acids, which should be efficiently oxidized in a carnitine-independent manner (22), would be just as stimulatory to GSIS in the fasted state as their long-chain counterparts. We have preliminary indications that this is not the case. An alternative explanation stems from the following consider- ations. Evidence is accumulating that, in the fed state, glucose metabolism in the $\beta$ cell leads to the generation of malonylCoA which, in turn, suppresses the activity of CPT I $(16,33$, $35,36)$. The expected result would be elevation of the cytosolic concentration of fatty acyl-CoAs (FA-CoA) derived either from blood-borne FFA or endogenous triacylglycerols. There is reason to believe that FA-CoAs might be important signaling molecules for insulin secretion $(16,33,35)$ and possible mechanisms have been reviewed (36). Should acetyl-CoA carboxylase in the $\beta$ cell undergo downregulation during starvation, as occurs in liver $(42,43)$ and also in insulinoma cells that are cultured in low vs high concentrations of glucose (35), malonyl-CoA synthesis would be compromised (regardless of the status of glucose transport or glucokinase activity). If so, the $\beta$ cell might be unable to elevate its cytosolic FA-CoA concentration when provided with glucose as sole substrate, and would thus exhibit inefficient insulin secretion. However, if a high external concentration of FFA is available, the FA-CoA deficit should be corrected and GSIS reinstated, as was seen here. If one of the functions of FA-CoA in the $\beta$ cell is to provide a source of phospholipids or diacylglycerol, both of which have been implicated in stimulus-secretion coupling (36), a source of glycerol-3-phosphate would also be needed. Ordinarily, this could only be derived from glucose, thus explaining why, in the fasted state, the $\beta$ cell requires both FFA and glucose for efficient insulin secretion. (This line of reasoning would be consistent with the observation that compounds such as 2-bromopalmitate and 2-bromostearate, which cannot be oxidized and, in fact, act as CPT I inhibitors, stimulate GSIS both in normal islets and in insulinoma cell lines, references 9 , 11, 16, 44. As CoA esters, these agents likely cause elevation of the cytosolic endogenous FA-CoA concentration and/or mimic the effects of natural FA-CoAs on some component of the insulin secretion machinery (16). However, the possibility that long-chain fatty acids and their 2-bromo derivatives might act directly to enhance GSIS [i.e., before their conversion into CoA esters] has not been formally excluded.) The fact that, in fed animals, artificial elevation of the plasma FFA level (or addition of palmitate to the medium in perfusion experiments) potentiated even the basal rate of insulin release might well reflect an already substantial flow of carbon from glucose or endogenous glycogen stores through glycolysis to malonyl-CoA. In this setting, it might be expected that the key elements needed for insulin secretion (i.e., ATP, glycerol-3-phosphate, a suppressed CPT I, and a threshold concentration of FA$\mathrm{CoA}$ ) are already in place, but at suboptimal levels. All would be exaggerated with a further rise in the glucose concentration, resulting in maximal efficiency of insulin secretion. While other formulations can be envisaged, we consider further speculation to be unwarranted at this time.

Finally, although the powerful synergism between FFA and glucose on $\beta$ cell activity upon termination of a fast must be regarded as a physiological component of fuel homeostasis, under other circumstances this same interaction could well have pathophysiological consequences. For example, it is possible that, as plasma FFA levels begin to rise in the early stages of obesity/non-insulin dependent diabetes syndromes, they contribute not only to the associated insulin resistance $(18,19)$, but also to the concomitant hyperinsulinemia through overstimulation of the $\beta$ cell. In addition, evidence is mounting that chronic hyperlipacidemia might be a factor in the failure of $\beta$ cell function as the disease process worsens $(45,46)$. 


\section{Acknowledgments}

We are indebted to Ben Alexander for expert technical assistance, including animal care and surgical techniques, and to Dr. Luciano Rossetti for advice on the clamp procedures.

This work was supported by grants from the National Institutes of Health (NIH)(DK-18573), the NIH/Juvenile Diabetes Foundation Diabetes Interdisciplinary Research Program, Sandoz Pharmaceuticals, the Chilton Foundation, and the Forrest C. Lattner Foundation, Inc.

\section{References}

1. Malaisse, W.J., F. Malaisse-Lagae, and P.H. Wright. 1967. Effect of fasting upon insulin secretion in the rat. Am. J. Physiol. 213:843-848.

2. Grey, N.J., S. Goldring, and D.M. Kipnis. 1970. The effect of fasting, diet, and actinomycin D on insulin secretion in the rat. J. Clin. Invest. 49:881889.

3. Bosboom, R.S., J. Zweens, and P.R. Bouman. 1973. Effects of feeding and fasting on the insulin secretory response to glucose and sulfonylureas in intact rats and isolated perfused rat pancreas. Diabetologia. 9:243-250.

4. Hedeskov, C.J., and K. Capito. 1974. The effect of starvation on insulin secretion and glucose metabolism in mouse pancreatic islets. Biochem. J. 140: 423-433.

5. Malaisse, W.J., A. Sener, and J. Levy. 1976. The stimulus-secretion coupling of glucose-induced insulin release. J. Biol. Chem. 251:1731-1737.

6. Levy, J., A. Herchuelz, A. Sener, and W.J. Malaisse. 1976. The stimulussecretion coupling of glucose-induced insulin release. XX. Fasting: a model for altered glucose recognition by the $\beta$-cell. Metab. Clin. Exp. 25:583-591.

7. Wolters, G.H.J., W. Konijnendik, and P.R. Bouman. 1977. Effects of fasting on insulin secretion, islet glucose metabolism and the cyclic adenosine $3^{\prime}, 5^{\prime}$-monophosphate content of rat pancreatic islets in vitro. Diabetes. 26:530537.

8. Burch, P.T., M.D. Trus, D.K. Berner, A. Leontire, K.C. Zawalich, and F.M. Matschinsky. 1981. Adaptation of glycolytic enzymes: Glucose use and insulin release in rat pancreatic islets during fasting and refeeding. Diabetes. 30: 923-928.

9. Tamarit-Rodriguez, J., E. Vara, and J. Tamarit. 1984. Starvation-induced changes of palmitate metabolism and insulin secretion in isolated rat islets stimulated by glucose. Biochem. J. 221:317-324.

10. Tamarit-Rodriguez, J., E. Vara, and J. Tamarit. 1984. Starvationinduced secretory changes of insulin, somatostatin, and glucagon and their modification by 2-bromostearate. Horm. Metab. Res. 16:115-119.

11. Bedoya, F.J., R. Ramirez, E. Arilla, and R. Goberna. 1984. Effect of 2-bromostearate on glucose-phosphorylating activities and the dynamics of insulin secretion in islets of Langerhans during fasting. Diabetes. 33:858-863.

12. Vara, E., and J. Tamarit-Rodriguez. 1986. Glucose stimulation of insulin secretion in islets of fed and starved rats and its dependence on lipid metabolism. Metab. Clin. Exp. 35:266-271.

13. Iwashima, Y., A. Kondoh-Abiko, S. Seino, J. Takeda, M. Eto, K.S. Polonsky, and I. Makino. 1994. Reduced levels of messenger ribonucleic acid for calcium channel, glucose transporter-2, and glucokinase are associated with alterations in insulin secretion in fasted rats. Endocrinology., 135:1010-1017.

14. Esser, V., M. Kuwajima, C.H. Krishnan, D.W. Foster, and J.D. McGarry. 1993. Inhibitors of mitochondrial carnitine palmitoyltransferase I limit the action of proteases on the enzyme. J. Biol. Chem. 268:5810-5816.

15. McGarry, J.D., M.J. Guest, and D.W. Foster. 1970. Ketone body metabolism in the ketosis of starvation and alloxan diabetes. J. Biol. Chem. 245: 4382-4390.

16. Chen, S., A. Ogawa, M. Ohneda, R.H. Unger, D.W. Foster, and J.D. McGarry. 1994. More direct evidence for a malonyl-CoA-carnitine palmitoyltransferase I interaction as a key event in pancreatic $\beta$-cell signaling. Diabetes. 43:878-883.

17. Balasse, E.O., and H.A. Ooms. 1973. Role of plasma free fatty acids in the control of insulin secretion in man. Diabetologia. 9:145-151.

18. McGarry, J.D. 1992. What if Minkowski had been ageusic? An alternative angle on diabetes. Science (Wash. DC). 258:766-770.

19. McGarry, J.D. 1994. Disordered metabolism in diabetes: have we underemphasized the fat component? J. Cell Biochem. 55:29-38.

20. Malaisse, W.J., F. Malaisse-Lagae, and D. Mayhew. 1967. A possible role for the adenylcyclase system in insulin secretion. J. Clin. Invest. 46:17241734.

21. McGarry, J.D., P.H. Wright, and D.W. Foster. 1975. Hormonal control of ketogenesis. Rapid activation of hepatic ketogenic capacity in fed rats by an- tiinsulin serum and glucagon. J. Clin. Invest. 55:1202-1209.

22. McGarry, J.D., K.F. Woeltje, M. Kuwajima, and D.W. Foster. 1989 Regulation of ketogenesis and the renaissance of carnitine palmitoyltransferase. Diabetes Metab. Rev. 5:271-284.

23. Declercq, P.E., J.R. Falck, M. Kuwajima, H. Tyminski, D.W. Foster, and J.D. McGarry. 1987. Characterization of the mitochondrial carnitine palmitoyltransferase enzyme system. I. Use of inhibitors. J. Biol. Chem. 262:98129821.

24. Greenough, W.B., S.R. Crespin, and D. Steinberg. 1967. Hypoglycaemia and hyperinsulinaemia in response to raised free-fatty-acid levels. Lancet. ii:1334-1336.

25. Seyffert, W.A., Jr., and L.L. Madison. 1967. Physiologic effects of metabolic fuels on carbohydrate metabolism. I. Acute effect of elevation of plasma free fatty acids on hepatic glucose output, peripheral glucose utilization, serum insulin, and plasma glucagon levels. Diabetes. 16:765-776.

26. Crespin, S.R., W.B. Greenough, and D. Steinberg. 1973. Stimulation of insulin secretion by long-chain free fatty acids. A direct pancreatic effect. $J$. Clin. Invest. 52:1979-1984.

27. Boden, G., X. Chen, J. Rosner, and M. Barton. 1995. Effects of a 48-h fat infusion on insulin secretion and glucose utilization. Diabetes. 44:1239-1242.

28. Malaisse, W.J., and F. Malaisse-Lagae. 1968. Stimulation of insulin secretion by noncarbohydrate metabolites. J. Lab. Clin. Med. 72:438-448.

29. Montague, W., and K.W. Taylor. 1968. Regulation of insulin secretion by short chain fatty acids. Nature (Lond.). 217:853.

30. Goberna, R., J. Tamarit, Jr., J. Osorio, R. Fussganger, J. Tamarit, and E.F. Pfeiffer. 1974. Action of $\beta$-hydroxy butyrate, acetoacetate and palmitate on the insulin release in the perfused isolated rat pancreas. Horm. Metab. Res. 6:256-260

31. Campillo, J.E., A.S. Luyckx, M.D. Torres, and P.J. Lefebvre. 1979. Effect of oleic acid on insulin secretion by the isolated perfused rat pancreas. Diabetologia. 16:267-273

32. Mokuda, O., Y. Sakamoto, H.-Y. Hue, R. Kawagoe, and N. Shimizu. 1993. Effects of long chain free fatty acids on glucose-induced insulin secretion in the perfused rat pancreas. Horm. Metab. Res. 25:596-597.

33. Corkey, B.E., M.C. Glennon, K.S. Chen, J.T. Deeny, F.M. Matschinsky, and M. Prentki. 1989. A role for malonyl-CoA in glucose-stimulated insulin secretion from clonal pancreatic $\beta$-Cells. J. Biol. Chem. 264:21608-21612.

34. Warnotte, C., P. Gilon, M. Nenquin, and J.-C. Henquin. 1994. Mechanisms of the stimulation of insulin release by saturated fatty acids: A study of palmitate effects in mouse $\beta$-cells. Diabetes. 43:703-711.

35. Brun, T., E. Roche, K.H. Kim, and M. Prentki. 1993. Glucose regulates acetyl-CoA carboxylase gene expression in a pancreatic $\beta$-cell line (INS-1). $J$. Biol. Chem. 268:18905-18911.

36. Newgard, C.B., and J.D. McGarry. 1995. Metabolic coupling factors in pancreatic $\beta$-cell signal transduction. Annu. Rev. Biochem. 64:689-719.

37. Madison, L.L., D. Mebane, R.H. Unger, and A. Lochner. 1964. The hypoglycemic action of ketones. II. Evidence for a stimulatory feedback of ketones on the pancreatic $\beta$-cell. J. Clin. Invest. 43:408-415.

38. Jenkins, D.J.A., W.M. Hunter, and D.V. Goff. 1970. Ketone bodies and evidence for increased insulin secretion. Nature (Lond.). 227:384-385.

39. Balasse, E.O., H.A. Ooms, and J.P. Lambilliotte. 1970. Evidence for stimulatory effect of ketone bodies on insulin secretion in man. Horm. Metab. Res. 2:371-372.

40. Unger, R.H., A.M. Eisentraut, L.L. Madison, K.R. Sims, and N. Whissen. 1963. The effects of total starvation upon the levels of circulating glucagon and insulin in man. J. Clin. Invest. 42:1031-1039.

41. Cahill, G.F., Jr., M.G. Herrera, A.P. Morgan, J.S. Soeldner, J. Steinke, P.L. Levy, G.A. Reichard, Jr., and D.M. Kipnis. 1966. Hormone-fuel interrelationships during fasting. J. Clin. Invest. 45:1751-1769.

42. McGarry, J.D., and D.W. Foster. 1980. Regulation of hepatic fatty acid oxidation and ketone body production. Annu. Rev. Biochem. 49:395-420.

43. Moir, A.M.B., and V.A. Zammit. 1990. Changes in the properties of cytosolic acetyl-CoA carboxylase studied in cold-clamped liver samples from fed, starved and starved-refed rats. Biochem. J. 272:511-517.

44. Prentki, M., S. Vischer, M.C. Glennon, R. Regazzi, J.T. Deeney, and B.E. Corkey. 1992. Malonyl-CoA and long chain acyl-CoA esters as metabolic coupling factors in nutrient-induced insulin secretion. J. Biol.Chem. 267:58025810 .

45. Lee, Y., H. Hiroshi, M. Ohneda, J.H. Johnson, J.D. McGarry, and R.H Unger. 1994. $\beta$-cell lipotoxicity in the pathogenesis of non-insulin-dependent diabetes mellitus of obese rats: impairment in adipocyte- $\beta$-cell relationships. Proc. Natl. Acad. Sci. USA. 91:10878-10882.

46. Zhou, Y.-P., and V.E. Grill. 1995. Long term exposure to fatty acids and ketones inhibits $\beta$-cell function in human pancreatic islets of Langerhans. $J$. Clin. Endocrinol. \& Metab. 80:1584-1590. 